\title{
LA ORGANIZACIÓN EN RED DEL PODER CORPORATIVO Una tipología de redes corporativas
}

NETWORK ORGANIZATION OF CORPORATE POWER

A typology of corporate networks

JuLláN CÁRdenas julian.cardenas@analisisderedes.com

Universidad de Antioquia. Colombia

\begin{abstract}
RESUMEN
Esta investigación surge de la inquietud por conocer cómo se organizan en red las grandes corporaciones del mundo. Estudiamos la estructura de poder corporativo o red formada por las corporaciones cuando comparten élites económicas (interlocking directorates). Analizamos las redes corporativas, mediante interlocking directorates, en diversos países del mundo para derivar empíricamente una tipología de redes corporativas que apunta a diferentes teorías de la organización del poder. Identificamos una red corporativa "elitista" basada en la unidad, centralización y control; y una red corporativa "pluralista", basada en la autonomía de las empresas, descentralización y enlaces de comunicación. Los resultados sugieren vías de investigación para averiguar cómo se configuran las redes y qué impactos tienen en la sociedad.
\end{abstract}

\section{Palabras Clave}

Análisis de redes; Élites; Interlocking directorates; Poder.

\begin{abstract}
This research arises from the interest in understanding how corporate power is organized around the world. We study the corporate power structure or corporate network when firms share directors (interlocking directorates). We analyze corporate interlock networks in various countries to empirically derive a typology of corporate networks that suggest different theories of the organization of power. We identify an "elitist" corporate network based on unity, centralization and control; and a "pluralist" corporate network based on members' autonomy, decentralization and communication ties. The results suggest avenues of research to find out how networks are configured and what impacts have on society.
\end{abstract}

\section{KEYWORDS}

Elites; Interlocking Directorates; Power; Social Networks Analysis. 


\section{INTRODUCCIÓN}

El estudio de la organización del poder corporativo es un reto teórico y metodológico fundamental para la sociología. La internacionalización de las economías, los enfrentamientos políticos y corporativos antes las fusiones y adquisiciones de empresas como Endesa o Banca Nazionale del Lavoro, el auge de la responsabilidad social corporativa, y los recientes escándalos financieros han reanimado el interés por averiguar qué sucede dentro de las estructuras de poder corporativo y las élites económicas. La estructura de poder es la red de organizaciones y posiciones dentro de una sociedad con capacidad de mantener el orden social, condicionar la economía y determinar la agenda política. La élite de poder es el conjunto de personas que ocupan posiciones dentro de la estructura de poder.

Las investigaciones más recientes sobre las estructuras de poder y élites aportan los conceptos de redes, tanto su metodología como su perspectiva teórica, para enfatizar los mecanismos relacionales como base de la organización del poder económico (Domhoff 2005; Knoke 1993; Scott 1990). Las redes sociales permiten descubrir el mapa de la estructura del poder. El estudio de los interlocking directorates - relaciones entre las corporaciones creadas cuando los consejeros pertenecen a varios consejos de administración simultáneamente- abarca a corporaciones y élites económicas, y permite construir las redes corporativas, las cuales son mapas de la organización del poder corporativo. El análisis de la organización del poder corporativo se convierte en una pieza esencial para entender las estrategias de negocios, las cosmovisiones de las élites, y las potenciales formas de influenciar las esferas políticas, económicas y sociales.

En este contexto, el presente artículo analiza las redes corporativas mediante interlocking directorates de diferentes países del mundo para apuntar empíricamente una tipología de redes corporativas que apunta a diferentes teorías de la organización del poder. Así, distinguimos entre redes corporativas Elitistas basadas en la cohesión, la centralización y el control, y redes corporativas Pluralistas basadas en la autonomía, la descentralización y la eficiencia. Esta tipología sirve de precedente para inspirar vías de investigación sobre los determinantes e impactos de las redes corporativas.

\section{La Organización del Poder}

Esta investigación nace de la inquietud por responder a la pregunta sobre cómo se organiza el poder corporativo (o empresarial) alrededor del mundo. En su análisis de la élite de poder, Mills (1956) destaca la unidad de la élite basada en la organización, y

\footnotetext{
"Investigación financiada por el Ministerio de Ciencia y Tecnología (SEC2003-02353) y el Ministerio de Ciencia e Innovación (SEJ2007-67714). Este trabajo ha sido posible gracias a las sugerencias y comentarios de Josep A. Rodríguez, Christian Oltra, Fredesvinda Mérida y Josep Lluís C. Bosch.
} 
especialmente en las redes y alianzas que mantienen sus miembros. Ello supone centrar la atención en la estructura relacional más que en la biografía como punto de partida de los análisis del poder. Más que en atributos, en relaciones sociales. Conocer la organización del poder es investigar sobre la estructura por la que se mueven y comunican los integrantes del poder. El análisis de esta organización nos acerca a desentrañar qué hacen y pueden hacer las élites y grandes corporaciones. Analizando cómo se organiza el poder corporativo podemos comprender y discutir sobre cómo funcionan las élites y qué sucede en la esfera económica.

Cuando las corporaciones entran en relación con otras configuran una red social. El conjunto de pautas de interacción entre las corporaciones (tanto su existencia como su ausencia) constituye la red corporativa o interorganización de las corporaciones. La red corporativa es considerada la organización del poder corporativo ya que señala cómo las empresas se estructuran y se distribuye el control. La construcción y análisis de la red corporativa nos ofrece la fotografía de los posibles canales de comunicación e influencia entre las grandes corporaciones, y el diferencial acceso a recursos por la pertenencia a redes, es decir la estructuración a partir del capital social ${ }^{1}$. Las investigaciones sobre la organización del poder se han centrado en "mapear" las estructuras de poder y élites, así como desarrollar una teoría general del poder (Domhoff 2005). Se han tratado de responder cuestiones como: quiénes son (Hunter 1959), dónde están (Domhoff 1967; Mills 1956), quién gana (Burris 2005; Mizruchi 1992), y qué pretenden (Useem 1984). Una de estas preguntas es cómo se organizan, la cual tratamos de abarcar mediante la identificación y el análisis de la red en la que se insertan las élites y grandes empresas, y que constituye la estructura de relaciones que puede condicionar la acción de los actores (Granovetter 1985).

Los análisis de las estructuras y élites de poder de Domhoff (1967) y Mills (1956) señalan que la unidad no es inherente en el poder económico o político, sino que debe ser construida mediante negociación e instituciones de resolución de conflictos, como escuelas comunes, enlaces familiares, o interlocking directorates. Useem (1984) enfatiza la unidad de las élites de poder y la centralización en un círculo íntimo del poder (inner circle) que defiende los intereses de toda la comunidad económica y política. Por otro lado, Robert Dahl (1961) en su análisis de la ciudad de New Haven destaca la descentralización del poder, y la separación de las élites económicas, las cuales compiten entre sí. En la misma línea, Rose (1967:92) subraya la pluralidad de intereses y grupos en el poder, y señala que los interlocking directorates son la excepción antes que la regla en el poder. Todo ello nos lleva a preguntarnos qué tipo de redes corporativas (o interorganizaciones de poder) se configuran e imperan hoy en los diversos países del mundo.

\footnotetext{
${ }^{1}$ El término capital social hace referencia a la pertenencia a redes sociales siguiendo la línea de autores como Ronald Burt (1992) que alude al capital social como "amigos, colegas, y contactos en general a través de los cuales recibes oportunidades de usar el capital financiero y humano" (1992:9); y de los trabajos de Bourdieu (1985), Coleman (1988) o Lin (1999a; 1999b).
} 


\section{Análisis de redes}

Aquello que distingue al análisis de redes de otras aproximaciones es que estudia la estructura directamente, ya que la unidad básica de trabajo y análisis es la relación social entre actores, y la estructura social es concebida como el conjunto de pautas de relación estables entre miembros de un sistema social. Esta red es una estructura ya que constriñe y posibilita la acción social de los actores. Además, mediante el uso de sociogramas, el análisis de redes nos permite visualizar la estructura o red social por la que se comunican los actores (Rodríguez 2005; Kilduff y Tsai 2003; Degenne y Forsé 1999; Wasserman y Faust 1994; Wellman y Berkowitz 1988).

La red corporativa es la estructura de enlaces corporativos, por lo que nos señala las limitaciones y posibilidades de acción de las corporaciones: control, influencia, comunicación, transferencia de capital, información, cooperación, competencia, autonomía. Sin embargo, el análisis cuantitativo de la red social no proporciona información sobre el contenido de la acción social, es decir, si la corporación A realmente controla a B, o si se produce un intercambio de información entre las empresas. Como bien aclara Windolf (2002:15) y otros académicos del análisis de redes (Scott 1990), la red corporativa es un mapa de las oportunidades y limitaciones creadas por las relaciones entre las corporaciones. Cuando señalamos que una estructura de redes corporativas presenta alta cohesión interpretamos y suponemos que se defienden intereses generales y se articulan acciones comunes. Desconocemos si realmente las corporaciones colaboran y aúnan intereses en redes cohesionadas, pero observamos que es viable la coordinación, ya que existen las oportunidades para ello, algo improbable si fueran redes fragmentadas. Por tanto, estudiamos el potencial uso de la red, y no la utilización de las redes. La red corporativa es por tanto una expresión de la organización del poder corporativo, no una evaluación de la acción social.

\section{Interlocking directorates}

Un interlocking directorate es la relación social que se establece entre las corporaciones cuando un consejero pertenece simultáneamente a varios consejos de administración. Existirá interacción entre la corporación $\mathrm{A}$ y $\mathrm{B}$, si la persona $\mathrm{X}$ está en el consejo de administración de $A$ y de $B$ al mismo tiempo. Cuando un consejero se sienta en la mesa de dos o más consejos de administración crea un enlace entre las corporaciones; el conjunto de enlaces compone una compleja red de relaciones. A la red de corporaciones se le denomina red corporativa; a las relaciones entre empresas, enlaces 0 interlocks corporativos; y a la persona que pertenece a varias corporaciones, consejero compartido. Por ejemplo, el señor Fernando Fernández Tapias pertenece a los consejos de administración de Unión Fenosa, Viajes Marsans, Real Madrid e Hispania Racing, por lo que crea unos interlocks o enlaces entre estas firmas. En términos gráficos, las corporaciones son los nodos y los consejeros compartidos las líneas que unen los nodos. 
Nos interesamos por los interlocking directorates como indicador relacional porque son pautas de relación estables (Davis, Yoo y Baker 2003) y aluden a las élites para relacionar a las corporaciones. La red de interlocking directorates es una expresión de la estructura de poder en tanto que engloba a las grandes corporaciones y a sus élites. Los análisis de interlocking directorates se han centrado principalmente en las grandes corporaciones, por lo que se asocia como una característica de los grandes negocios y una estrategia de las élites de poder. Los interlocking directorates ocurren también entre las empresas medianas, aunque es un fenómeno más común entre las grandes corporaciones (Harrigan 2006).

El crecimiento del análisis de redes desde los años 80 ha incentivado exponencialmente el estudio de las estructuras de poder y las élites. Uno de los éxitos de los análisis de redes corporativas e interlocking directorates es su capacidad de representación y estudio del espacio interorganizacional tan relevante a nivel teórico (Granovetter 1985; DiMaggio y Powell 1983; Pfeffer y Salancik 1978; Lawrence y Lorsch 1967; Gouldner 1954; Selznick 1949). En los últimos años se han sucedido constantemente los análisis a nivel nacional, e incluso a nivel internacional (Carroll 2009; Cárdenas 2006; Rodríguez, Cárdenas y Oltra 2006; Kentor y Jang 2004; Carroll y Fennema 2002)22.

Sin embargo, los análisis comparativos de redes corporativas han sido escasos. Los únicos predecesores en la identificación de las diferencias y similitudes entre redes corporativas son los estudios realizados por Stokman, Ziegler y Scott (1985) y el de Windolf (2002). Ambas obras son referencias indiscutibles en la literatura de análisis comparativo de redes corporativas de interlocking directorates. El primero, llevado a cabo por el grupo de investigación Research Group of Intercorporate Strcucture reunido por Stokman, Ziegler y Scott en Networks of Corporate Power (1985), se realiza sobre diez países. Los autores realizan un estudio descriptivo de las redes corporativas entre las 250 mayores empresas de cada país. La relevancia de la investigación de Stokman, Ziegler y Scott (1985) radica en la consistencia y globalidad del estudio. El otro gran estudio de comparación entre países sobre redes corporativas es el realizado por Paul Windolf, Corporate Networks in Europe and the United States (2002). La obra del autor alemán analiza seis países de Europa y Norteamérica: Alemania, Francia, Países Bajos, Suiza, Reino Unido y Estados Unidos, y compara indicadores estadísticos de redes, los más destacados son densidad, componentes, centralización y multiplicidad. Windolf apunta a la influencia de las legislaciones en la forma o configuración de la red corporativa. Ambas obras manejan gran cantidad de información y abarcan Norteamérica y Europa; no incluyen países de Asia ni Oceanía. Otras investigaciones que realizan análisis comparativos de más de dos redes corporativas son Scott (1987) entre Reino Unido, Estados Unidos y Japón; y Kogut y Belinky (2008) entre Alemania, Suecia, Dinamarca, Noruega, Suiza, Países Bajos con datos de los años 90 y el año 2000.

${ }^{2}$ Para mayor detalle véase Mizruchi (1996) y Kono et al. (1998). 
Sin embargo, se encuentra la falta de una tipología de redes corporativas de interlocking directorates. La identificación de tipos de redes corporativas resulta importante a nivel teórico para establecer el punto de partida de investigaciones sobre los determinantes de la red, y las consecuencias o impactos de la red en las esferas políticas, económicas y sociales. Por ello, creemos que hay necesidad de un examen actualizado, sistemático y global de redes corporativas. Nuestra aportación se concreta en la realización de un análisis comparativo entre países, la ampliación del número de casos (países), la reformulación y sistematización del análisis de redes en dimensiones para el examen de las redes corporativas de interlocking directorates, la actualización de los datos para 2005 y la identificación de tipos de redes corporativas. De esta manera nos aproximamos a conocer las diversas formas de organización del poder corporativo en el mundo.

\section{DiseÑo}

Para la selección de los casos (países) que vamos a estudiar tomamos como referente instituciones destacadas que hayan podido influir en el desarrollo de diferentes formas o configuraciones de redes. La literatura de variedades de capitalismo (Hall y Gingerich 2009; Amable 2005; Hall y Soskice 2001) nos señala la relevancia de lógicas diversas como el mercado, el Estado y el corporativismo en el desarrollo y persistencia de diferentes organizaciones económicas o capitalismos. Tomando como referencia estas lógicas seleccionamos casos paralelos. De esta manera, escogemos países donde el mercado es la lógica básica de coordinación: EE.UU, Reino Unido, Canadá, Australia (Hall y Gingerich 2009; Amable 2005; Schmidt 2002); donde el Estado ha sido clave en la financiación y propiedad de las empresas: Francia, Italia, España, Suecia (Amable 2005; Schmidt 2002); y donde el corporativismo es el mecanismo central en el capitalismo: Alemania, Suiza, Países Bajos, Japón (Hall y Gingerich 2009; Amable 2005; Moerland 1995). Mediante el análisis de casos diferentes y otros a priori similares, tratamos de representar y caracterizar las diversas redes corporativas y presentar una tipología.

La delimitación del tamaño de la red se realiza seleccionando aquellas corporaciones con un mayor tamaño e impacto económico. Para ser sistemáticos en el análisis comparativo, seleccionamos las 50 mayores corporaciones de cada país. Concretamente 50 por trabajar con redes de tamaño mediano que faciliten la visualización de la red, y concentración en las más grandes empresas. Un número menor de 50 puede traer conclusiones poco significativas ${ }^{3}$. Estas corporaciones no tienen por qué ser

\footnotetext{
${ }^{3}$ No hay una cifra que pueda considerarse correcta, ya que es el investigador quien sitúa los límites de la red y los análisis previos han variado desde las 30 corporaciones (Murray 2001) hasta las 600 (Davis, Yoo y Baker 2003).
} 
representativas del resto de empresas del país en cuanto a organización y estrategias, pero sí son aquellas con mayor capacidad operativa en la economía. Mediante la selección de esta muestra perdemos generalización pero ganamos en capacidad comparativa y visualización de la red. Para seleccionar las 50 mayores corporaciones empleamos como criterio de clasificación los ingresos anuales. Los ingresos son el criterio más equivalente y alcanzable por las corporaciones independientemente del sector económico al que pertenezcan ${ }^{4}$. Los listados de las 50 mayores corporaciones en cada uno de los 12 países y de los consejos de administración se obtienen a partir de la base de datos de Hoover's $(2005)^{5}$ que no incluye cajas de ahorro debido a su carácter jurídico de fundación privada. Construimos una matriz de dos modos con el listado de corporaciones y consejeros compartidos y la transformamos en una de un modo. Esta matriz es la base para poder representar y analizar la red corporativa. La red corporativa es un sistema de relaciones entre las corporaciones vinculadas entre sí por compartir consejeros ${ }^{6}$.

\section{Dimensiones de la red}

Analizamos tres aspectos o dimensiones de la red -la cohesión, centralización y multiplicidad- desarrolladas por el análisis de redes como partes constituyentes de la organización social (Rodríguez 2005; Sanz Menéndez 2003; Wasserman y Faust 1994; Scott 1991). Estas tres dimensiones estructurales nos sirven para caracterizar a las redes e interpretar y discutir qué posibilidades de acción y limitaciones se dan para las corporaciones y élites. Estos aspectos de la estructura social permiten comparar las redes corporativas de manera pautada y sistemática. Cada una de estas dimensiones es evaluada utilizando indicadores generales de la red ${ }^{7}$.

La cohesión es una dimensión relevante del análisis de la red porque indica potenciales formas de integración, identificación y colaboración. Altos niveles de cohesión pueden

\footnotetext{
${ }^{4}$ Si optásemos por la cifra de ventas como criterio de clasificación de las mayores corporaciones, dentro de la muestra de las 50 mayores, la mayoría serían empresas industriales. Si nos inclinamos por los activos, en la muestra de las 50 mayores corporaciones prácticamente todas serían financieras. Mientras que el indicador de capitalización bursátil, utilizado por Rodríguez (2003; 2000) o Krempel (2006), solo permite centrarse en aquellas compañías que cotizan en bolsa.

${ }^{5}$ En caso de información incompleta del consejo de administración o no disponible, recurrimos a las páginas web de las corporaciones correspondientes, y si el caso lo requiere a los informes anuales (annual reports) de las empresas.

${ }^{6}$ La construcción de matrices, el procesamiento de los datos, el cálculo de indicadores y su representación en sociogramas se realiza con el programa informático-estadístico de análisis de redes sociales Ucinet 6 (Borgatti, Everett y Freeman 2002).

${ }^{7}$ El término de indicadores generales de la red es empleado aludiendo a las características de la red social en conjunto, y así distinguirlas de aquellas medidas o indicadores individuales referidos a la posición específica de cada nodo (corporación).
} 
ser asociados con acciones colectivas, posibilidades de coordinación y articulación de intereses. Para corporaciones que compiten en un mismo mercado, los enlaces suelen resolver las incertidumbres y reducir la desconfianza (Schoorman, Bazerman y Atkin 1981; Pfeffer y Salancik 1978; Pfeffer 1972). Es una forma potencial de colaboración, facilita el consenso y puede favorecer una visión compartida de la realidad. Por otro lado, la alta cohesión también supone mayores índices de control social en tanto los actores son alcanzables y tienen mayor probabilidad de poder ser controlados por el resto. Cuando la cohesión de la red es baja, los actores son más autónomos y están menos susceptibles a las influencias externas y al control social. Los indicadores de redes sociales para medir la cohesión de las redes corporativas son: la "densidad" y la "cohesión basada en la distancia"8.

La centralización es la dimensión de la red que indica si la cohesión y actividad de la red depende de unos pocos actores centrales. Una alta centralización indica que la información se encuentra monopolizada por unos pocos actores, que la cohesión de la red se basa en estos actores más centrales. Una red menos centralizada implica mayor libertad de los actores, menos dependencia, organización más flexible y abierta, y mayor participación de todos en los flujos de comunicación. Para medir la centralización de la red empleamos, en primer lugar, el indicador de "centralización basado en el grado"9. Este indicador sirve para averiguar en qué medida un grafo está o no organizado en torno a sus puntos más centrales. Aunque no nos indica si esos puntos están dispersos por el grafo o, por el contrario, forman un núcleo central en el grafo. Para solventar estos supuestos utilizamos otro indicador de centralización: "la alcanzabilidad del actor más central según grado", que es el porcentaje de actores de la red a los que el actor más central puede alcanzar directamente y nos indica tanto su poder como su capacidad de centralización ${ }^{10}$.

La multiplicidad es la cantidad de relaciones que convergen en un enlace y señala la intensidad de las relaciones. Cuantas más relaciones existan en un mismo enlace, mayor es la multiplicidad. Una relación intercorporativa puede ser simple (un consejero une dos empresas) o múltiple (las dos empresas se unen por dos consejeros o más). La multiplicidad se mide por el porcentaje de relaciones múltiples sobre el total de

\footnotetext{
${ }^{8}$ Para calcular la densidad y el resto de los indicadores de redes sociales utilizamos la matriz dicotomizada. En la matriz dicotomizada las celdas son 001 , donde 0 indica ausencia de relación entre dos nodos, y 1 indica existencia de relación aunque sin especificar la intensidad de la relación. En una matriz no-dicotomizada las celdas contienen el número exacto de enlaces entre dos nodos. Para definición de estos indicadores véase el Anexo.

${ }^{9}$ Las medidas de centralización, resultado del trabajo de Freeman durante los años 70 , están todas basadas en las distancias entre puntos y todas ellas definen los grafos como centralizados en la medida en que sus puntos están todos cerca (Freeman 1978/1979). Para una descripción detallada véase Anexo.

${ }^{10}$ En este caso el actor es central por el número de relaciones directas que tiene (grado), es decir, por el número de consejeros compartidos que tiene la corporación. Para una descripción detallada véase el Anexo.
} 


\section{Gráfico 1.1. Redes corporativas elitistas.}
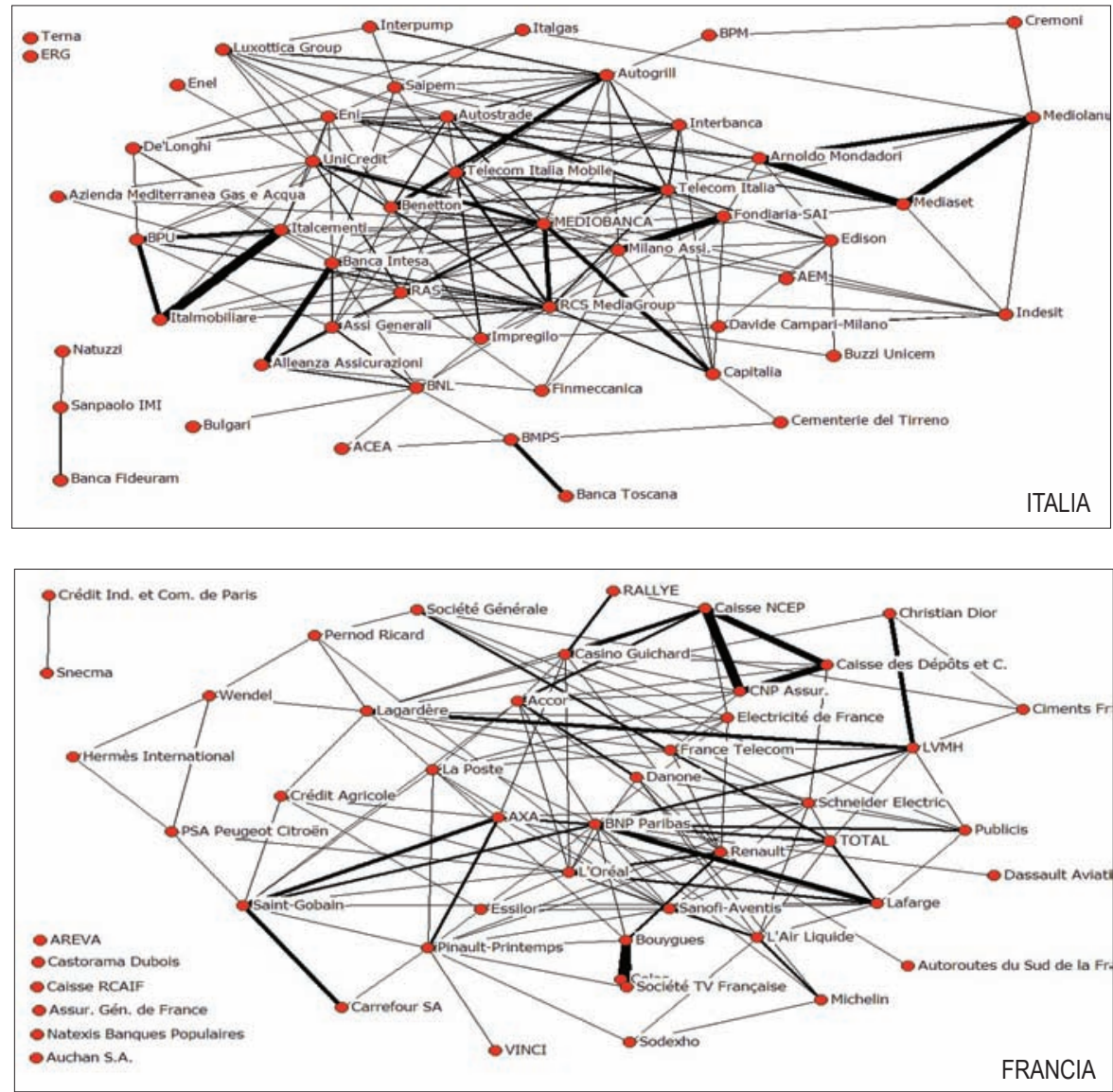

"Interlocking directorates de las 50 mayores corporaciones de cada país. Los nodos son las corporaciones, y las líneas son los consejeros compartidos.

relaciones ${ }^{11}$. Un porcentaje alto de relaciones múltiples (multiplicidad) sugiere que la relación entre las corporaciones es intensa, por lo que se refuerza el compromiso entre las partes. Además el mantener dos o más consejeros para establecer un mismo enlace puede apuntar a un objetivo de controlar las decisiones del consejo de administración. Incluso, el mantener más efectivos para unir dos mismas empresas puede suponer un

${ }^{11}$ Para mayor descripción en el cálculo véase Anexo. 
Gráfico 1.1. Redes corporativas elitistas (cont.).
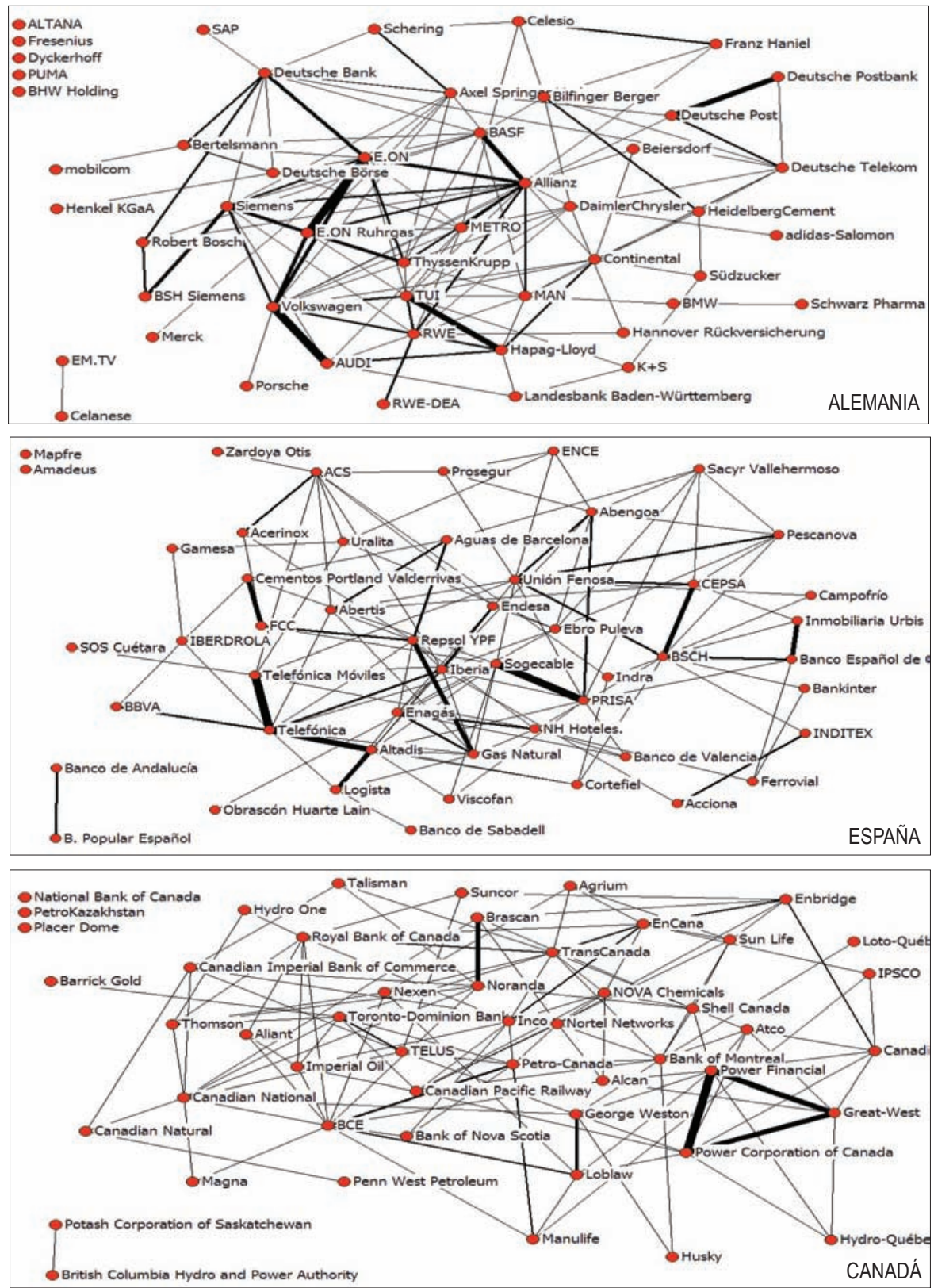

"Interlocking directorates de las 50 mayores corporaciones de cada país. Los nodos son las corporaciones y las líneas son los consejeros compartidos. 
mayor coste de mantenimiento posiblemente en forma de capital accionarial. En cambio, cuando las corporaciones mantienen relaciones simples (comparten un solo consejero) el enlace cumple la misma función de comunicación que podrían hacer dos o tres consejeros y a menor coste, lo que sugiere más eficiencia relacional.

\section{ANÁLISIS}

\section{Cohesión}

La "densidad" nos indica cuán inclusiva es la red y lo calculamos a partir del número de relaciones existentes sobre el total de relaciones posibles. Las redes de Alemania, España, Francia, Italia y Canadá están por encima del 0,10 del total de enlaces posibles. A nivel intermedio, entre un 0,7 y 0,8 de relaciones existentes sobre el total de las relaciones posibles, encontramos las redes de Países Bajos, Suecia, Estados Unidos y Australia. Finalmente con muy baja densidad relacional se encuentran las estructuras de Suiza, Reino Unido y Japón, ambas con índices menores al 0,4 (tabla 1). Hay redes corporativas como las de Alemania, España o Italia con el triple de relaciones que las redes del Reino Unido o Suiza, a pesar de ser vecinos continentales.

La "cohesión basada en la distancia" está basada en el cálculo de la probabilidad de unión completa de los actores a un paso. A partir de este indicador estadístico observamos que la red italiana es la más solidaria, seguida de España, Canadá, Francia, Alemania, Australia y Estados Unidos. Con un índice menor están las redes de Países Bajos y Suecia. Redes muy fragmentadas son las de Suiza y Reino Unido. Finalmente Japón presenta un índice de cohesión muy bajo, lo que señala la altísima fragmentación de la red nipona, ya que además de tener un alto número de corporaciones aisladas, aquellas empresas con enlaces ni tan siquiera forman una estructura compacta. En Japón imperan las relaciones diádicas o triádicas, es decir, entre dos o tres actores (gráfico 1.2).

\section{Centralización}

Las redes corporativas de Italia y Francia son las más centralizadas, seguidas de cerca por la estructura de Alemania. La alta cohesión y comunicación en la red corporativa, que constatábamos en estos países europeos, es favorecida por unos actores centrales con acceso a gran parte de la red. En Italia y Francia, el actor con mayor centralidad tiene acceso directo (a un paso) a casi la mitad de los miembros de la red. En Italia las corporaciones más centrales son bancos y compañías de seguros, lo que señala el alto relacional de las financieras. En cambio, en Francia las corporaciones más centrales -BNP Paribas, Total, Schneider Electric, Lafarge, Axa, Air Liquide, Sanofi-Aventis y Pinault- son de diversos sectores económicos. Estas empresas parecen formar un holding 
o grupo económico de enlaces intensos alrededor del banco BNP Paribas y con amplio acceso a la periferia de la red.

En Alemania, las corporaciones más centrales son siderometalúrgicas. Esta tradicional industria pesada del país germano se agolpa alrededor de la aseguradora Allianz, empresa que controla los mayores canales de comunicación en la red y auténtico centro neurálgico de la red alemana. La compañía de seguros Allianz tiene acceso directo a un tercio de la red. Cabe destacar la posición periférica de los bancos, excepto Deutsche Bank. Parece que los bancos, anteriormente actores centrales en la red corporativa (Fohlin 1999) se desplazan a la periferia y tal vez abandonan su posición central de accionistas en Alemania.

En España, el indicador de centralización es alto $(0,17)$, aunque sin alcanzar los niveles de sus vecinos mediterráneos. La cohesión de la red española se secunda gracias al protagonismo que adquieren las corporaciones energéticas de distribución de electricidad, gas y agua. Las corporaciones energéticas acostumbran a ser la mesa de reunión de los poderes fácticos de la banca y los gobiernos central y regionales (Rodríguez y Cárdenas 2006). Al ser empresas de suministro universal y servicio público están reguladas por el gobierno en lo que respecta a tarifas, tasas y servicios. Debido a este sensible enlace con el Ejecutivo, las élites económicas parece que buscan cooptar asientos en el consejo de administración de las empresas de distribución de electricidad, luz y agua. En Suecia, las corporaciones centrales son principalmente empresas siderometalúrgicas con vínculos entre sí, por lo que podemos hablar de colusión o relaciones intrasectoriales, aquí también con un banco como eje neurálgico, Investor AB.

Por otra parte, se encuentran una serie de redes corporativas con un grado de centralización medio: Canadá, Australia, y Suiza. En Canadá las corporaciones centrales son petroleras y bancos, las cuales están cohesionadas entre sí formando una fuerte unión de interés posiblemente debido a las inyecciones de capital necesitadas por las empresas de explotación de petróleo y la pretensión de los bancos de controlar a las empresas con mayores beneficios de Canadá, además de una de las fuentes principales de energía en el mundo. En Australia las corporaciones más centrales son mayoritariamente bancos. Hay diferentes centros de poder alrededor de los grandes bancos, Australia and New Zealand Bank, Commonwealth Bank, Westpac Banking y con corporaciones dedicadas a la alimentación como intermediadoras entre estos bancos.

El caso de la red corporativa de Suiza presenta características diferentes, debido a que es una red poco cohesionada y sin un centro de poder claro. La centralización de la red en Suiza es media, debido a la existencia de diversos centros de poder. No hay un solo centro, sino holdings económicos alrededor de compañías de seguros. Hay relación entre los holdings aunque con excesivos puntos de corte $^{12}$, lo que señala la fragilidad de

\footnotetext{
${ }^{12}$ El punto de corte es aquel actor que conecta diversas subregiones de la red. Su desaparición rompería la unión de la red en diversas subredes. Es un actor clave por su posición de intermediación y cohesión de la red. La alta presencia de puntos de corte en una red señala excesiva dependencia sobre estos actores para mantener la unión de la red.
} 


\section{Gráfico 1.2 Redes corporativas pluralistas}
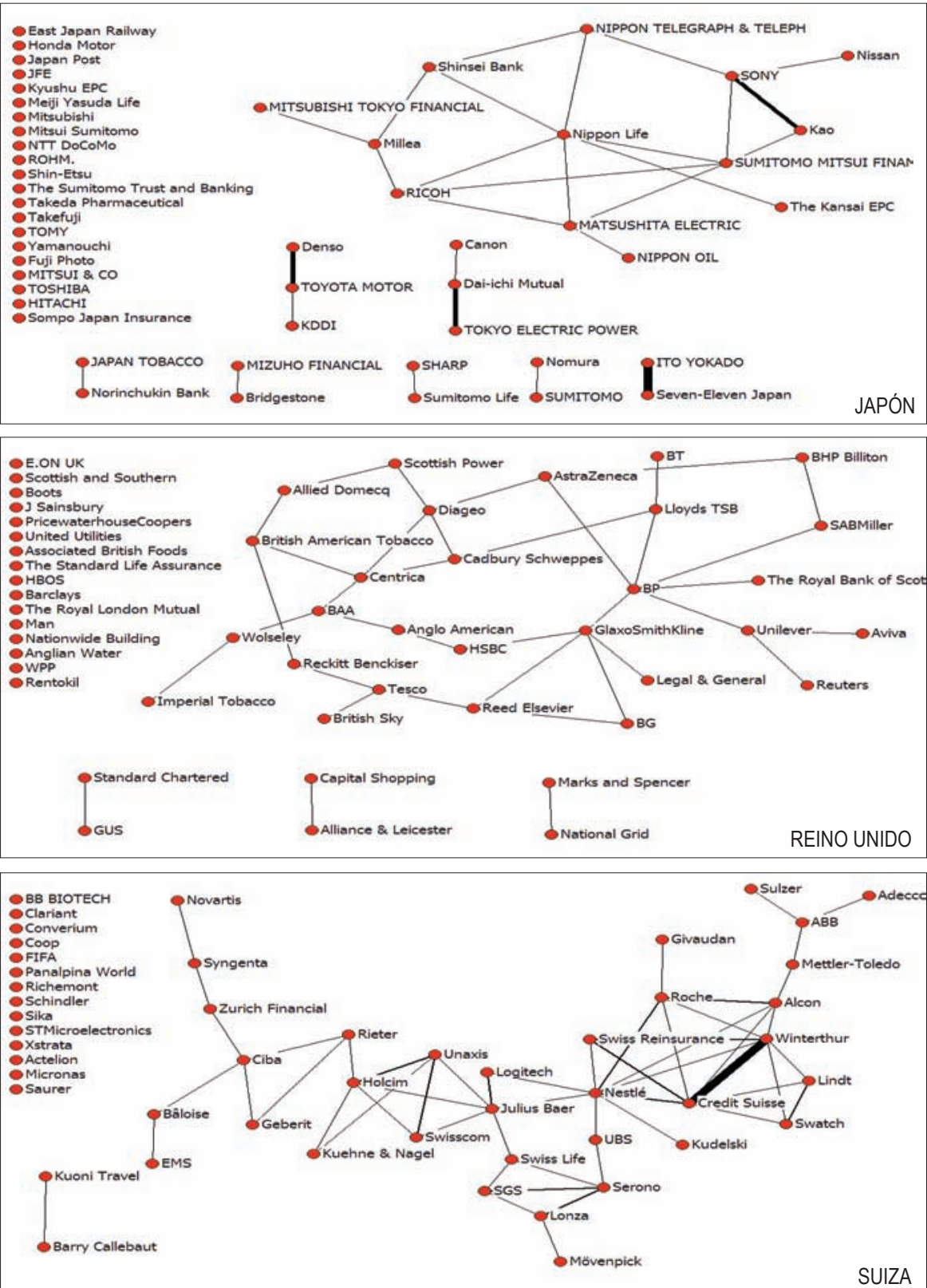

"Interlocking directorates de las 50 mayores corporaciones de cada país. Los nodos son las corporaciones, y las líneas son los consejeros compartidos. 
Gráfico 1.2 Redes corporativas pluralistas (cont.).
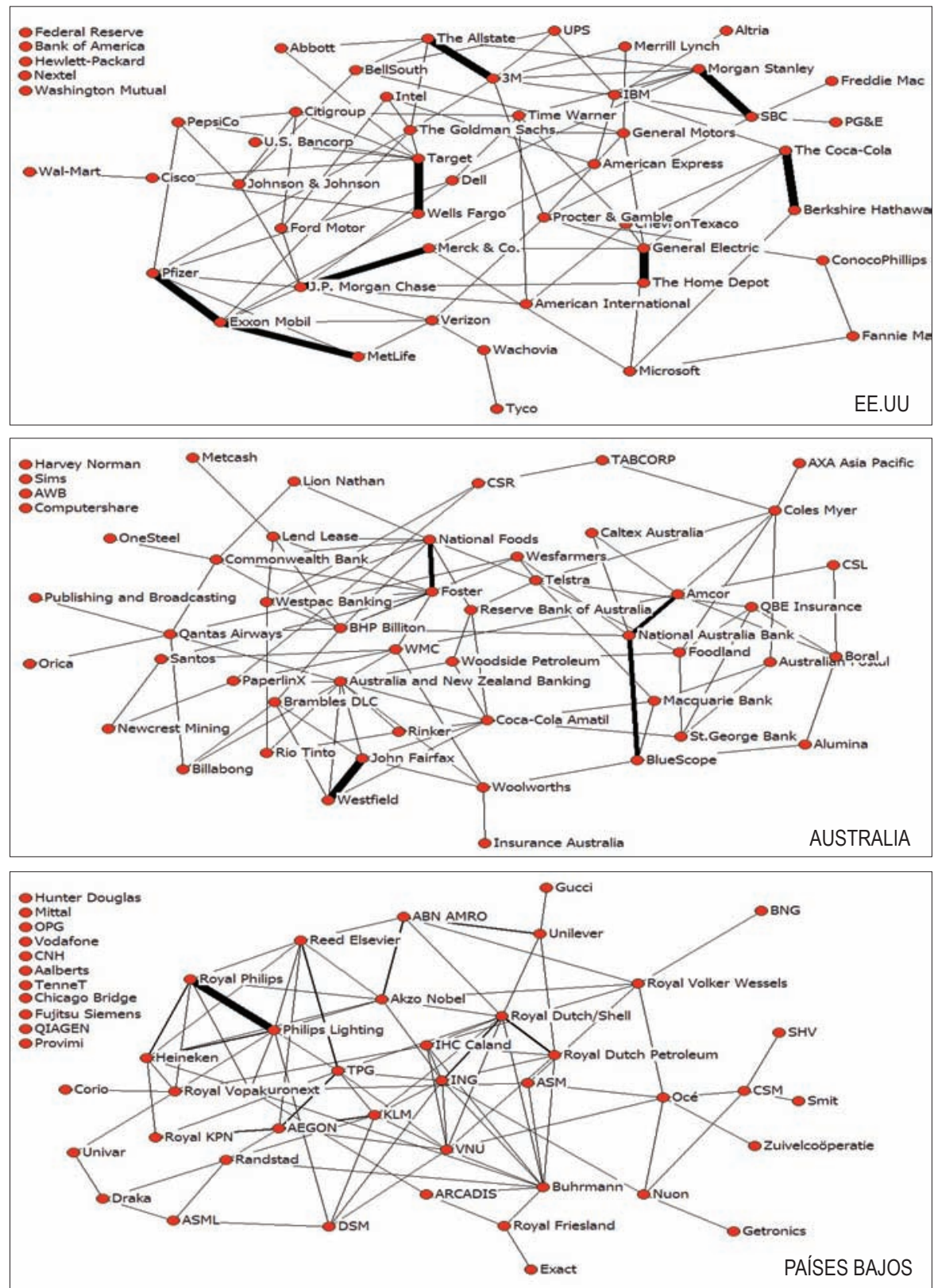

"Interlocking directorates de las 50 mayores corporaciones de cada país. Los nodos son las corporaciones, y las líneas son los consejeros compartidos. 
Gráfico 1.2 Redes corporativas pluralistas (cont.).

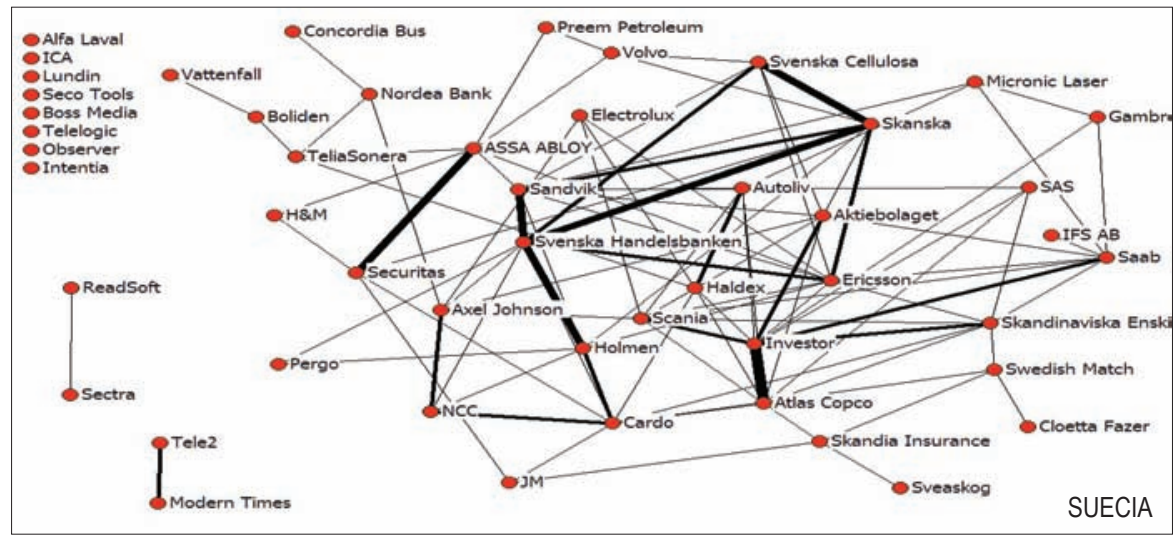

*Interlocking directorates de las 50 mayores corporaciones de cada país. Los nodos son las corporaciones, y las líneas son los consejeros compartidos.

Tabla 1.

Indicadores generales de la red.

\begin{tabular}{lccccc}
\hline & \multicolumn{2}{c}{ Cohesión } & \multicolumn{2}{c}{ Centralización } & Multiplicidad \\
\hline & Densidad & $\begin{array}{c}\text { Cohesión } \\
\text { basada en la } \\
\text { distancia }\end{array}$ & $\begin{array}{c}\text { Centralización } \\
\text { de grado }\end{array}$ & $\begin{array}{c}\text { Alcanzabilidad } \\
\text { del actor más } \\
\text { central }\end{array}$ & $\begin{array}{c}\text { Relaciones } \\
\text { múltiples }\end{array}$ \\
\hline Italia & 0,14 & 0,42 & 0,28 & 0,42 & 0,37 \\
\hline Francia & 0,11 & 0,36 & 0,27 & 0,41 & 0,28 \\
\hline Canadá & 0,11 & 0,39 & 0,14 & 0,26 & 0,25 \\
\hline Alemania & 0,10 & 0,35 & 0,21 & 0,33 & 0,31 \\
\hline España & 0,10 & 0,40 & 0,17 & 0,27 & 0,23 \\
\hline Suecia & 0,08 & 0,27 & 0,15 & 0,26 & 0,21 \\
\hline Países Bajos & 0,08 & 0,27 & 0,13 & 0,26 & 0,18 \\
\hline Australia & 0,08 & 0,35 & 0,15 & 0,24 & 0,05 \\
\hline EEUU & 0,07 & 0,32 & 0,12 & 0,20 & 0,08 \\
\hline Suiza & 0,04 & 0,16 & 0,15 & 0,25 & 0,29 \\
\hline Reino Unido & 0,03 & 0,12 & 0,10 & 0,18 & 0,00 \\
\hline Japón & 0,02 & 0,04 & 0,10 & 0,21 & 0,15 \\
\hline Media & 0,08 & 0,29 & 0,16 & 0,27 & 0,20 \\
\hline Desv. Típica & 0,04 & 0,12 & 0,06 & 0,08 & 0,11 \\
\hline Funte: Eland & & & &
\end{tabular}

Fuente: Elaboración propia. 
la comunicación y la alta dependencia de unos consejeros concretos (gráfico 1.2). Es una organización de poder corporativo caracterizada por una baja cohesión, unos costes elevados de comunicación y un bajo control social. Se otorga enorme protagonismo a determinados consejeros debido a su posición de nexo entre las corporaciones del país. Finalmente, encontramos las redes corporativas menos centralizadas: Países Bajos, Estados Unidos, Reino Unido y Japón. Estas cuatro redes presentan un índice de centralización de grado bajo (alrededor del 0.10 ), lo que nos señala que el poder no se halla concentrado en una serie concreta de actores. El actor central alcanza de forma directa solo a una quinta parte de la red, por lo que sus dominios son limitados. Los centros de poder están dispersos en las redes de Países Bajos, EEUU y Reino Unido, y completamente separados en el caso de Japón.

\section{Multiplicidad}

Cuanto mayor sea la proporción de relaciones múltiples en la red habrá más relaciones de control, ya que dos o más consejeros para un mismo enlace insinúan que además del objetivo de comunicación se busca influenciar y controlar a la otra corporación. Además hay mayor compromiso y pertenencia al reforzar la alianza entre empresas, al mismo tiempo que supone un mayor coste de mantenimiento. Por el contrario, cuanto menos relaciones múltiples, se intuye una mayor tendencia a la búsqueda de la información, menos pretensiones de control y supervisión, y mayor eficiencia relacional.

La red corporativa de Reino Unido se supone como la red de eficiencia y comunicación ya que no hay ninguna relación múltiple. Los enlaces entre corporaciones son creados siempre por un solo consejero. No hay relaciones intensas o líneas gruesas entre las corporaciones (gráfico 1.2). Aunque una corporación pueda tener varios enlaces, cada uno es protagonizado o mantenido por una sola persona. Las corporaciones buscan entablar comunicación antes que controlar otras empresas. Además, la comunicación entre élites corporativas no necesita de varios puentes y, por tanto, la inversión en el mantenimiento de las relaciones es más baja. Son redes menos costosas de mantener. También se aproximan a la idea de redes de información y eficiencia, las redes de Estados Unidos y Australia. Parece ser que los países anglosajones apuestan por reducción de costes y pretensiones de información antes que control.

En cambio, las redes de Italia y Alemania tienen una alta proporción de relaciones múltiples y, por tanto, son redes que sugieren control y parecen requerir alta inversión. Una de cada tres relaciones intercorporativas en Italia y Alemania son múltiples, es decir, la unión entre dos corporaciones se produce por dos o más consejeros. Además de obtener información y establecer relaciones de negocios, parece que se tiene como objetivo ejercer influencia de una corporación sobre otra. Para mantener estas redes de control, las corporaciones puede que deban invertir en capital accionarial y dedicar esfuerzos a ejercer este control, por lo que las redes italiana y alemana son de alto coste, y parecen solicitar un mayor grado de compromiso entre las partes. En esta situación también se encuentran las redes corporativas de Francia y Suiza. El caso helvético es curioso ya 
que la red suiza es poco cohesionada y, al mismo tiempo, se presenta como una red con alta proporción de relaciones de control. Tienen un nivel intermedio las estructuras de Canadá, España, Suecia y Países Bajos.

Los indicadores de densidad y cohesión basada en la distancia son transformados en un índice único de cohesión que oscila entre 0 y 1, donde 1 señala cohesión máxima y 0 fragmentación completa. Asimismo, los indicadores de centralización de grado y alcanzabilidad del actor más central son agrupados para la creación de un índice único de centralización que oscila entre 0 y 1, donde 1 indica completa centralización en un solo actor, y 0 indica nula centralización. De esta manera disponemos de tres variables para representar y describir la forma o configuración de las redes corporativas (gráfico 2).

\section{Análisis de Cluster}

Para identificar distintos tipos de redes corporativas empleamos el análisis de cluster. El análisis de cluster agrupa a los países en grupos, los cuales presentan una alta homogeneidad interna y una alta heterogeneidad externa. Realizamos un análisis de cluster en dos etapas para optimizar los beneficios de cada algoritmo. En primer lugar un análisis de cluster jerárquico para identificar el número apropiado de clusters e identificar los puntos iniciales que actúen de centroides. Estos resultados sirven para, en segundo lugar, realizar un análisis de cluster no-jerárquico mediante K-medias (donde $k$ es el

Gráfico 2.

Dimensiones de la red corporativa y casos

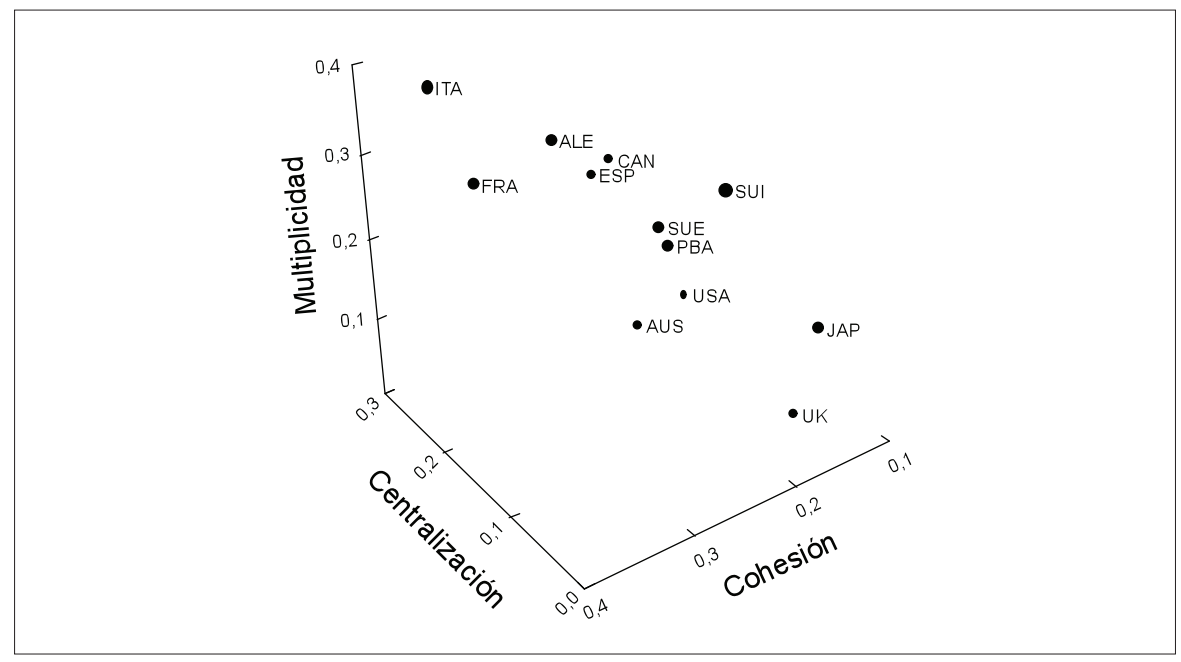


número de clusters elegido). Este procedimiento aumenta la validación de los resultados (Punj y Stewart 1983; Milligan 1980), y es ampliamente usado para la identificación de clusters (Ketchen y Shook 1996).

Las tres variables construidas que describen la red corporativa -cohesión, centralización, multiplicidad- son seleccionadas para ejecutar el análisis de cluster. Las variables son estandarizadas mediante Z scores. Aplicamos el procedimiento de cluster jerárquico mediante el método de Ward, debido a que presenta soluciones superiores a otros algoritmos jerárquicos (Mojena 1977). Para determinar el número óptimo de clusters (regla de parada), visualizamos los saltos significativos en el dendograma y utilizamos los métodos de Calinski y Harabasz, y Duda y Hart Je(2)/Je(1) ${ }^{13}$, ambas apuntadas como las técnicas idóneas (Milligan y Cooper 1985). La solución más apropiada fluctúa entre dos y tres clusters. Optamos finalmente por 2 clusters debido a que presentan mayores diferencias tras aplicar una validación mediante el test de Anova ${ }^{14}$.

Para clasificar los países en los dos clusters identificados aplicamos un análisis de cluster de K-medias. Se seleccionan los centroides anteriormente identificados y se aplica un procedimiento iterativo reduciendo los sesgos de la partición inicial de método jerárquico y de la existencia de casos atípicos (Hair et al. 1998). Para validar los resultados empleamos el test de Anova, el cual señala que los clusters presentan diferencias significativas $(p<0.05)$ en cuanto a las tres variables (tabla 2$)$.

Tabla 2.

Diferencias de medias entre los clusters

\begin{tabular}{lcccc}
\hline & Cluster 1 $(n=5)$ & $\begin{array}{c}\text { Cluster 2 } \\
(n=7)\end{array}$ & $F$ & Sig. \\
\hline Cohesión & 0,25 & 0,14 & 11,39 & 0,007 \\
Centralización & 0,28 & 0,18 & 12,70 & 0,005 \\
Multiplicidad & 0,29 & 0,14 & 9,38 & 0,012 \\
\hline
\end{tabular}

Fuente: Elaboración propia.

\footnotetext{
${ }^{13}$ La regla de parada de Calinski y Harabasz (pseudo F) señala qué nivel jerárquico máximo indica el número correcto de particiones en los datos (Calinski y Harabasz 1974). Duda y Hart (1973) señalan que para decidir el número de clusters se determina según el mayor valor Je(2)/Je(1) (0.5818) que corresponde a un valor bajo de pseudo T-cuadrado (4.31) y que tenga un T-cuadrado mayor arriba y abajo.

${ }^{14}$ En la solución de 2 clusters la variable cohesión presentaba diferencias significativas entre clusters $(p<0.05)$, pero no en la solución de 3 clusters.
} 


\section{Los dos tipos de redes corporativas}

El análisis de los datos muestra la existencia de dos tipos de redes corporativas. El primer tipo son redes caracterizadas por una alta cohesión, es decir, un alto número de enlaces entre las grandes corporaciones lo cual puede promover la unidad y la articulación de intereses conjuntos; una alta centralización, aludiendo a que dentro de la propia élite económica hay un grupo selecto de actores que por sus capacidades relacionales son el centro neurálgico o núcleo del poder; y una alta multiplicidad, lo cual sugiere búsqueda de mayor control y refuerzo de alianzas. Denominamos este tipo como red Elitista, rescatando la distinción entre elitismo y pluralismo que la sociología política y la ciencia política señalan como dos formas de organización de los intereses y el poder. Dentro de este tipo de red corporativa Elitista se incluyen las redes de Italia, Francia, Alemania, España y Canadá.

El otro tipo de red corporativa la denominamos Pluralista ya que las redes se caracterizan por una baja cohesión, insinuando que prima la actividad individual antes que la acción colectiva. Estas redes no están centralizadas; dentro del espacio corporativo se estructuran diferentes centros de poder o posiciones relevantes, lo que sugiere mayor competencia. La proporción de relaciones múltiples es baja, por lo que las redes corporativas parecen formarse con prioridades de información antes que de control. Dentro de este tipo de red corporativa Pluralista se enmarcan las redes de Reino Unido, Japón, Estados Unidos, Australia, Suiza, Países Bajos y Suecia.

Las redes corporativas Elitistas son redes de integración del poder, con potenciales facilidades de comunicación entre los actores. Se favorecen las oportunidades de cooperación y consenso. Los costes de comunicación entre las élites económicas son bajos, lo que puede permitir más fácilmente la difusión de la información. Son redes de alta solidaridad y unidad. Aunque, al mismo tiempo, son espacios corporativos con alto control social; el alto número de relaciones entre las corporaciones deja poco margen a la actividad individual y a la autonomía de la empresa. La proporción de relaciones múltiples es elevada lo que sugiere que las corporaciones entablan relaciones múltiples con el fin de buscar el control sobre otras empresas.

En cambio, las redes corporativas Pluralistas son fragmentadas, lo que supone una mayor autonomía para las corporaciones, y una menor relevancia de la red como forma de organización y acción. La articulación de acciones comunes se vislumbra complicada debido a que no existen vías potenciales de cooperación mediante las élites. La dinámica de la red no depende de unos actores centrales por lo que el riesgo está más distribuido. Los dominios del actor más central son limitados, no alcanza a gran parte de los actores de la red. El control está más distribuido. Parece que se busca la eficiencia en la formación de enlaces, reduciendo todo vínculo que no aporte nuevas fuentes de comunicación.

Sin embargo, la red corporativa Pluralista presenta una peculiaridad que otorga gran centralidad y dominio a las corporaciones que actúan como puentes entre secciones de la red. La presencia de gran número de puntos de corte (actores que unen por sí solos 
diferentes partes de la red y cuya desaparición rompería la unión de la red) señala la alta dependencia de unas corporaciones determinadas. Este hecho confirma la preponderancia y hegemonía de los actores individuales sobre el colectivo. En el tipo de red Elitista la desaparición por recesión o crisis de un actor no trastocaría la organización completa debido a la diversidad de caminos de acceso y comunicación. En cambio, en el tipo de red Pluralista la baja densidad relacional y la excesiva presencia de puntos de corte otorga gran poder a estos actores intermediarios.

El categorizar a las redes corporativas en un continuo entre elitistas y pluralistas, además de crear un instrumento de análisis para el análisis de las redes de poder, permite ver el valor diferenciado que se otorga a la autonomía de la corporación y a la competencia en la parte más alta del poder económico. La red Elitista parece fomentar la colaboración, la regulación de la competencia, y valora en mayor medida la unión la autonomía. En cambio, la organización en red Pluralista se basa en la autonomía de los actores, la capacidad individual en la consecución de sus fines de supervivencia, y en potenciar la alta competencia entre las grandes corporaciones. Las empresas del modelo Pluralista parecen tener mayores capacidades individuales, ya que no requieren de apoyo local o unión nacional para su supervivencia.

\section{Discusión: Vías de INVESTIGACIÓN}

\section{Determinantes}

Una vez descritas las diferencias y similitudes entre las redes corporativas, surge la pregunta de cómo explicarlas. ¿Cómo se explican las diferencias y similitudes entre las redes corporativas de los diversos países? El objetivo sería buscar las causas 0 determinantes que nos ayuden a comprender por qué existen y se mantienen diferencias y similitudes en las formas de organizar el poder económico alrededor del mundo.

En clara alusión a Granovetter (1985), Zukin y DiMaggio (1990) apuntan que además de la inserción en redes, se produce una inserción cognitiva, cultural y política. Las corporaciones están insertas en diversas redes e instituciones al mismo tiempo, y algunas son las causas de otras. Es decir, la inserción institucional de las corporaciones explicaría la inserción relacional. Por tanto, explicaríamos el tipo de red corporativa (Elitista o Pluralista) a partir de la inserción de las grandes corporaciones en estructuras institucionales. ¿Cuáles? El reto está en analizar qué parte del entorno institucional condiciona la formación de enlaces de la empresa.

En primer lugar, podría ser la "estructura financiera" que hace referencia al origen de los fondos financieros de las empresas. Si las relaciones financieras dominantes se producen o bien con los bancos o bien con los mercados de capitales, ello determinará la relación entre las empresas financieras y no-financieras, los costes de transacción y así el valor de las redes de interlocking directorates como medio de control de la inversión 
y cooptación de inversores. En segundo lugar, la "estructura política" y sus políticas de intervención podrían favorecer un tipo de red corporativa u otra. En tercer lugar, la "estructura de propiedad" de las empresas - la relación entre accionistas y consejerospodría determinar el tipo de red en función de la creación de enlaces entre empresas de propiedad común.

Finalmente, la estructura internacional, es decir, las relaciones internacionales de las corporaciones y los países podrían condicionar la forma de la red corporativa hacia el elitismo o el pluralismo para afrontar la entrada de capital extranjero y la formación de redes transnacionales. En los análisis de redes corporativas, a la internacionalización de las economías se le atribuye la responsabilidad de erosionary disolver la red corporativa (Höpner y Krempel 2003; Windolf 2002), o redefinirla (Heemskerk y Fennema 2009; Rodríguez 2003; Barnes y Ritter 2001), aunque sin aportar demostración empírica. Todas estas estructuras o instituciones donde la corporación está inserta señalan líneas de investigación e hipótesis de trabajo para un análisis de los determinantes del tipo de redes corporativas.

\section{Impactos}

El análisis de las consecuencias de la pertenencia a redes ha sido una constante en los estudios de redes e interlocking directorates, tal vez como estrategia para legitimar la importancia de las redes y los enlaces corporativos. Mizruchi (1992) demostró que la posición de las corporaciones en la red corporativa condiciona su actividad política medida por las donaciones empresariales a las campañas presidenciales. Investigaciones similares relacionando interlocking directorates y donaciones a las campañas electorales son llevadas a cabo por Burris (2005) en EE.UU y Bond (2007) en Reino Unido. La investigación de interlocking directorates y comportamiento financiero es el campo de trabajo de Mark Mizruchi y Linda Stearns durante varios años (Mizruchi y Stearns 2001; 1994; Stearns y Mizruchi 1993; Mizruchi y Stearns 1988), siempre con la voluntad de señalar que el comportamiento es fruto de la posición en la estructura relacional.

Uno de los dilemas con los que han topado los investigadores de redes corporativas ha sido responder a si los enlaces o interlocks y la posición de la empresa en la red condiciona los resultados económicos de las empresas. Algunos trabajos han encontrado efectos positivos de los interlocking directorates en los beneficios de la empresa (Burt 1983; Pennings 1980), mientras otros han encontrado efectos negativos (Fligstein y Brantley 1992). Cronin y Popov (2006) con datos recientes del Reino Unido concluyen que, aun existiendo relación entre interlocks y rentabilidad empresarial, ésta es débil y coyuntural. Estas investigaciones han surgido sobre todo en las escuelas de negocios, donde académicos e investigadores se siguen preguntando para qué sirven los interlocking directorates. Si los beneficios económicos de los enlaces corporativos o interlocks no son claros, si las élites tienen otros espacios de interacción como clubes sociales o lobbies, por qué se siguen empleando hoy en día.

La mayoría de los estudios han tratado de explicar el comportamiento individual de las empresas según su posición en la red o sus enlaces. Sin embargo, hacen falta 
investigaciones que midan el impacto de la red en la economía completa, en la esfera política 0 en asuntos sociales. Preguntas como si consolidar una red Elitista genera mayores índices de gobernabilidad, si restringe el crecimiento de nuevas empresas, o si reduce el conflicto social entre patronal y sindicatos, surgen al reflexionar sobre el impacto político, económico y social de la red corporativa. Estas cuestiones suponen dar un paso más allá y estudiar complementariedades institucionales donde una institución favorece a otra institución (Kogut y Ragin 2006; Amable 2005; Hall y Soskice 2001).

La aproximación metodológica del análisis comparativo cualitativo mediante fuzzy set métodos (fsQCA) resulta óptima para emprender estos estudios: 1) posibilitaría el análisis causal con una muestra reducida de casos, 2) superaría las limitaciones de las técnicas de regresión que asumen relación lineal, 3) facilitaría la reducción de la complejidad mediante la construcción de categorías fuzzy, y 4) permitiría estudiar la posibilidad de que múltiples rutas lleven a un mismo resultado (equifinality) (Ragin 2000).

Además de continuar con el análisis de los determinantes e impactos de las redes de corporaciones, nuestras futuras líneas de investigación se dirigen a estudiar las pertenencias de los consejeros a organizaciones políticas, sociales y económicas con el propósito de entender cómo influyen en la sociedad. La ocupación de posiciones en las fundaciones, agrupaciones políticas, o clubes deportivos por parte de las élites puede ser una forma de demostrar su influencia en la esfera social. Otra de las posibles derivaciones del estudio es ampliar la muestra de corporaciones, incluyendo la región de América Latina no analizada hasta el momento. La red latinoamericana es un campo de estudio interesante para comprender los procesos de cambio de régimen político, conociendo si en ellos se produce una circulación o cambio de élites. Incluso, cabe averiguar si los intentos de construcción de espacios continentales como Mercosur o la Comunidad Suramericana de Naciones van acompañados de un incremento de los interlocking directorates internacionales y la formación de una élite continental. Finalmente, una nueva línea de investigación está dirigida a analizar las fusiones, adquisiciones y opciones públicas de adquisición (OPAS) ya que las compras y ventas de corporaciones suponen procesos de expansión y conquista de redes.

\section{Conclusiones}

Tras los diversos análisis y discusiones, debemos preguntarnos si conocemos mejor cómo está organizado el poder corporativo. La respuesta a esta cuestión es afirmativa. El empleo del análisis de redes nos ha ayudado a ver y entender realidades que van más allá de una corporación o un país. El análisis de redes completas permite entender las acciones de las élites y las corporaciones que se posibilitan y limitan según el tipo de estructura. Además, nos ha permitido vislumbrar que por muy similares que parezcan los poderosos, las formas de organización en red son y serán diversas según el país. 
La red de tipo Elitista presenta una alta cohesión. El poder corporativo mantiene potenciales caminos de cooperación, amplias fuentes de recursos, facilidades de comunicación y vías para articular acciones comunes. Las corporaciones parecen sufrir un fuerte control social y poco margen para autonomía individual. La centralización de la red es elevada y hay una alta proporción de relaciones múltiples ya que los enlaces corporativos pueden funcionar como mecanismos de control. Es el caso de Italia, Francia, Alemania, España y Canadá.

La red de tipo Pluralista es una red fragmentada, de baja cohesión. Los costes de comunicación se suponen altos y las oportunidades de acción colectiva bajas. Parece apostarse por la autonomía en la dirección de las corporaciones. La centralización de la red es mínima. A pesar de que pueda haber centros de poder, estos no consiguen tener acceso a gran parte de la red, por lo que los costes para emprender acciones comunes se intuyen elevados y con excesiva dificultad de consenso. El poder está más desenfocado, sin un único centro claro y visible. El acceso a recursos depende en ciertos casos de actores clave que constituyen los diferentes centros de poder en la comunicación y articulación de la red. Se sugiere que son redes de comunicación antes que de control, por lo que se reduce todo lo que no suponga una nueva fuente de información. La corporación individual tiene más relevancia y sufre menor control social por parte de otras corporaciones. Los intereses parecen estar más diversificados y la autonomía es el medio para el desarrollo y la competencia en el mercado. En este tipo encajan las redes de Reino Unido, Japón, Estados Unidos, Australia, Suiza, Países Bajos y Suecia.

La creación de una tipología de redes corporativas nos ha permitido crear vías de investigación para valorar el impacto o resultados cuando se desarrolla un tipo de red u otra, así como para estudiar las causas que determinan la forma o configuración de la red. Cuando países o continentes se plantean formar redes (o romperlas) necesitan saber sus determinantes y valorar sus impactos. El escribir y tipificar las redes es una herramienta de análisis para entender la organización del poder corporativo, y para ir descifrando cómo construir o fragmentar redes.

\section{REFERENCIAS BibLIOGRÁFICAS}

Amable, B. 2005. Les Cinq Capitalismes: Diversité des Systèmes Économiques et Sociaux dans la Mondialisation. París: Seuil.

Barnes, R. y E. R. Ritter. 2001. "Networks of Corporate Interlocking: 1962-1995." Critical Sociology 27: 192-220.

Bond, M. 2007. "Élite Social Relations and Corporate Political Donations in Britain." Political Studies 55:59-85.

Borgatti, S. P., M. G. Everett y L. C. Freeman. 2002. Ucinet for Windows: Software for Social Network Analysis. Harvard: Analytic Technologies. 
Bourdieu, P. 1985. "The Social Space and the Genesis of Groups." Social Science Information 24:195-220.

Burris, V. 2005. "Interlocking Directorates and Political Cohesion among Corporate Élites". American Journal of Sociology 111: 249-283.

Burt, R. 1983. Corporate Profits and Cooptation. Nueva York: Academic Press.

Burt, R. 1992. Structural Holes: The Social Structure of Competition. Cambridge: Cambridge University Press.

Calinski T. y J. Harabasz. 1974. "A Dendrite Method for Cluster Analysis." Communications in Statistics 3:1-27.

Cárdenas, J. 2006. "La Visualización de los Interlocks Globales". Pp. 63-94 en Sociología para el Futuro, editado por J. A. Rodríguez. Barcelona: Icaria.

Carroll, W. K. 2009. "Transnationalists and National Networkers in the Global Corporate Elite." Global Networks 9:289-314.

Carroll, W. K. y M. Alexander. 1999. "Finance Capital and Capitalist Class Integration in the 1990s: Networks of Interlocking Directorships in Canada and Australia". The Canadian Review of Sociology and Anthropology 36:331-354.

Carroll, W. K. y M. Fennema, 2002. "Is There a Transnational Business Community?" International Sociology 17:393-419.

Coleman, J. S. 1988. "Social Capital in the Creation of Human Capital." American Journal of Sociology 94:95-120.

Cronin, B. y V. Popov. 2006. "Director Networks and UK Corporate Performance." Paper presentado en Politics and Interlocking Directorates, 28-29 de septiembre, Barcelona.

Dahl, R. A. 1961. Who Governs? New Haven: Yale University Press.

Davis, G. F., M. Yoo y W. E. Baker. 2003. "The Small World of the American Corporate Elite, 1982-2001". Strategic Organization 1:301-326.

Degenne, A. y M. Forsé, 1999. Introducing Social Networks. Londres: Sage.

DiMaggio, P. J. y W. W. Powell. 1983. "The Iron Cage Revisited: Institutional Isomorphism and Collective Rationality in Organizational Fields." American Sociological Review 48:147-160.

Domhoff, G. W. 1967. Who Rules America? Englewood Cliffs: Prentice-Hall.

Domhoff, G. W. 2005. "Who Rules America.net". Consultado 17 de mayo 2010 (http://sociology.ucsc. edu/whorulesamerica/).

Duda R. O. y P. E. Hart. 1973. Pattern Classification and Scene Analysis. Nueva York: John Wiley and Sons. 
Fligstein, N. y P. Brantley. 1992. "Bank Control, Owner Control, or Organizational Dynamics: Who control the Large Modern Corporations?." American Journal of Sociology 98:280-307.

Fohlin, C. 1999. "The Rise of Interlocking Directorates in Imperial Germany." Economic History Review 52:307-333.

Freeman, L. C. 1978/1979. "Centrality in Social Networks: A Conceptual Clarification." Social Networks 1: $215-239$

Gouldner, A. 1954. Patterns of Industrial Bureaucracy. Nueva York: The Free Press.

Granovetter, M. 1985. "Economic Action and Social Structure: The Problem of Embeddedness." The American Journal of Sociology 91:481-510.

Hair, J. E., R. Anderson, R. L. Tatham y W. C. Black. 1998. Multivariate Data Analysis. Englewood Cliffs, $\mathrm{NJ}$ : Prentice-Hall.

Hall, P. A. y D. W. Gingerich. 2009. "Varieties of Capitalism and Institutional Complementarities in the Macroeconomy: An Empirical Analysis." British Journal of Political Science 39:449-482.

Hall, P. A. y D. W. Soskice. 2001. "An Introduction to Varieties of Capitalism". Pp. 1-70 en Varieties of Capitalism: The Institutional Foundations of Comparative Advantage. Oxford: Oxford University Press.

Harrigan, N. 2006. "Political Power and Political Divisions within Australian and New Zealand Business". Paper presentado en Politics and Interlocking Directorates, 28-29 de septiembre, Barcelona.

Heemskerk, E. M. y M. Fennema. 2009. "Network Dynamics of Dutch Business Élite". International Sociology 24:807-832.

Hoover's. 2005. "Hoover's Pro." Consultado 21 de septiembre 2009 (www.hoovers.com).

Höpner, M. y L. Krempel. 2003. "The Politics of the German Company Network". Working Paper Series 03-9. Max Planck Institute for the Study of Societies MPIfG. Colonia.

Hunter, F. 1959. Top leadership, U.S.A. Chapel Hill: University of North Carolina Press.

Kentor, J. y Y. S. Jang. 2004. "Yes, there is a (Growing) Transnational Business Community: A Study of Global Interlocking Directorates 1983-98". International Sociology 19:355-368.

Ketchen Jr., D. J. y C. L. Shook. 1996. "The Application of Cluster Analysis in Strategic Management Research: An Analysis and Critique". Strategic Management Journal 17:441-458.

Kilduff, M. y W. Tsai. 2003. Social Networks and Organizations. Thousand Oaks: Sage.

Knoke, D. 1993. "Networks of Elite Structure and Decision Making." Sociological Methods \& Research 22:23-45.

Kogut, B. y M. Belinky. 2008. "Comparing Small World Statistics over time and across Countries: An Introduction to the Special Issue Comparative and Transnational corporate networks." European Management Review 5:1-10. 
Kogut, B. y C. Ragin. 2006. "Exploring Complexity when Diversity is Limited: Institutional Complementarity in Theories of Rule of Law and National Systems Revisited". European Management Review $3: 44-59$

Kono, C., D. Palmer, R. Friedland y M. Zafonte. 1998. "Lost in Space: The Geography of Corporate Interlocking Directorates". The American Journal of Sociology 103:863-911.

Krempel, L. 2006. "Changing Capital Ties among the 100 Largest German Companies between 1996 and 2004". Paper presentado en Politics and Interlocking Directorates, 28-29 de septiembre, Barcelona.

Lawrence, P. R. y J. W. Lorsch. 1967. "Differentiation and Integration in Complex Organizations". Administrative Science Quarterly 12:1-47.

Lin, N. 1999a. "Building a Network Theory of Social Capital". Connections 22:28-51.

Lin, N. 1999b. "Social Networks and Status Attainment." Annual Review of Sociology 25:467-487.

Milligan, G. W. 1980. "An Examination of the Effect of Six Types of Error Perturbation on Fifteen Clustering Algorithms." Psychometrika 45:325-342.

Milligan, G. W. y M. C. Cooper. 1985. "An Examination of Procedures for Determining the Number of Clusters in a Data Set." Psychometrika 50:159-179.

Mills, C. W. 1956. The Power Elite. Nueva York: Oxford University Press.

Mizruchi, M. S. 1992. The Structure of Corporate Political Action: Interfirm Relations and their Consequences. Cambridge: Harvard University Press.

Mizruchi, M. S. 1996. "What Do Interlocks Do? An Analysis, Critique, and Assessment of Research on Interlocking Directorates." Annual Review of Sociology 22:271-298.

Mizruchi, M. S. y L. B. Stearns. 1988. "A Longitudinal Study of the Formation of Interlocking Directorates". Administrative Science Quarterly 33:194-210.

Mizruchi, M. S. y L. B. Stearns. 1994. "A Longitudinal Study of Borrowing by Large American Corporations." Administrative Science Quarterly 39:118-140.

Mizruchi, M. S. y L. B. Stearns, 2001. "Getting Deals Done: The Use of Social Networks in Bank Decision-Making." American Sociological Review 66:647-671.

Moerland, P. 1995. "Corporate Ownership and Control Structures: An International Comparison". Review of Industrial Organization 10:443-464.

Mojena R. 1977. "Hierarchical Grouping Methods and Stopping Rules: An Evaluation". Computer Journal 20:359-363.

Mosca, G. 1939. The Ruling Class. Nueva York: McGraw-Hill.

Murray, G. 2001. "Interlocking Directorates: What do they Tell about Corporate Power in Australia." Journal of Australian Political Economy 4:5-26. 
Pennings, J. M. 1980. Interlocking Directorates. San Francisco: Jossey-Bass.

Pfeffer, J. 1972. "Size and Composition of Corporate Boards of Directors: The Organization and its Environment". Administrative Science Quarterly 17:218-228.

Pfeffer, J. y G. Salancik. 1978. The External Control of Organizations: A Resource Dependence Perspective. Nueva York: Harper \& Row.

Popov, V. (2006) "Interlocking Directorate and Corporate Performance in the United Kingdom: Social Network Analysis of Director Interlocks on Layers of Different Profitability". Paper presentado en XXVI International Sunbelt Social Network Conference, 24-30 de abril, Vancouver.

Punj G. y D. W. Stewart. 1983. "Cluster Analysis in Marketing Research: review and suggestions for application." Journal of Marketing Research 20:134-148.

Ragin, C. C. 2000. Fuzzy-set Social Science. Chicago: University of Chicago Press.

Rodríguez, J. A. 2003. "Revisitando el poder: Cambios en la estructura social del poder en España (1991-2000)." Sistema 172:3-26.

Rodríguez, J. A. 2005. Análisis estructural y de redes. Madrid: CIS.

Rodríguez, J. A. y J. Cárdenas. 2006. "Politics and Interlocking Directorates". Paper presentado en Politics and Interlocking Directorates, 28-29 de septiembre, Barcelona.

Rodríguez, J. A., J. Cárdenas y C. Oltra. 2006. "Redes de Poder Económico en Europa". Sistema 194: 3-44.

Rose, A. M. 1967. The Power Structure: Political Process in American Society. Oxford: Oxford University Press.

Sanz Menéndez, L. 2003. "Análisis de Redes Sociales. O cómo representar las estructuras sociales subyacentes". Apuntes de Ciencia y Tecnología 7:21-29.

Schmidt, V. A. 2002. The Futures of European Capitalism. Oxford: Oxford University Press.

Schoorman, F. D., M. H. Bazerman y R. S. Atkin. 1981. "Interlocking Directorates: A Strategy for Reducing Environmental Uncertainty". Academy of Management Review 6:243-251.

Scott, J. 1987. "Intercorporate Structure in Britain, the United States and Japan". Pp. 307-320 en The Sociology of Élites, vol. II editado por J. Scott. 1990. Cheltenham: Edward Elgar.

Scott, J. 1991. Social Network Analysis: A Handbook. Londres: Sage.

Scott, J. ed. 1990. The Sociology of Élites: Volumes I, II, III. Cheltenham: Edward Elgar.

Selznick, P. 1949. TVA and the Grass Roots. Berkeley: University of California Press.

Stearns, L. B. y M. S. Mizruchi. 1993. "Board Composition and Corporate Financing: The Impact of Financial Institution Representation on Borrowing". Academy of Management Journal 36:603. 
Stokman, F., R. Ziegler, y J. Scott. eds. 1985. Networks of Corporate Power: A Comparative Analysis of Ten Countries. Nueva York: Basil Blackwell.

Useem, M. 1984. The Inner Circle. Nueva York: Oxford University Press.

Wasserman, S. y K. Faust. 1994. Social Network Analysis: Methods and Applications. Cambridge: Cambridge University Press.

Wellman, B. y S. D. Berkowitz, comps. 1988. Social Structure: A Network Approach. Nueva York: Cambridge University Press.

Windolf, P. 2002. Corporate Networks in Europe and the United States. Nueva York: Oxford University Press.

Zukin, S. y P. DiMaggio. 1990. "Structures of Capital: The Social Organization of the Economy: Introduction". Pp. 1-36 en Structures of Capital: The Social Organization of the Economy, editado por S. Zukin y P. DiMaggio. Cambridge: Cambridge University Press.

JULIÁN CÁRDENAS es Doctor y Licenciado en Sociología por la Universidad de Barcelona. Actualmente es profesor en el Departamento de Sociología de la Universidad de Antioquia (Colombia) donde imparte investigación cuantitativa, análisis de redes y sociología económica y comercial. Es consultor y formador en www. analisisderedes.com. Ha trabajado como profesor en la Universidad de Barcelona, en IL3 y como investigador en IESE Business School. Sus principales áreas de interés son las élites, análisis de redes, capital social, emprendedores y análisis cualitativo comparativo (QCA). Pertenece a los grupo de investigación Redes y Actores Sociales, al grupo Estudios de Poder y Privilegio y a Politics and Interlocking Directorates Research Community.

RECIBIDO: $\quad 04 / 09 / 2010$

ACEPTADO: $10 / 01 / 2011$ 


\begin{abstract}
AneXo
DENSIDAD: es la proporción de relaciones existentes sobre el total de relaciones posibles. La densidad oscila entre 0 y 1 , donde los extremos representan una red totalmente desconectada $(0)$ y una red donde todos los actores están directamente relacionados con todos (1) (Rodríguez 2005; Scott 1991). Describe el nivel general de interacción entre las corporaciones en la estructura. Cuanto mayor sea la densidad, más inclusiva y compacta será la red.

COHESIÓN BASADA EN LA DISTANCIA: es un indicador estadístico basado en el cálculo de probabilidad de la unión completa de los actores a un paso según las distancias geodésicas (Borgatti, Everett y Freeman 2002). La distancia de camino, o camino de distancia es el número de líneas que separa a dos nodos. La distancia geodésica es el número mínimo de líneas que deben ser atravesadas para unir dos puntos. Es decir, la longitud del camino más corto que une a dos actores (Degenne y Forsé 1999; Wasserman y Faust 1994). Cuando esta distancia no es cero, un actor es alcanzable por otro, lo que significa que existe un canal de comunicación por el que un mensaje puede ser transmitido de un actor a otro. La cohesión basada en la distancia oscila entre 0 y 1 , donde valores próximos a 0 indican red fragmentada, y valores cercanos a 1 alta cohesión entre los actores de la red.
\end{abstract}

CentRALIZACIÓN DE GRADO: la centralización de la red según grado mide el nivel en que la centralidad del punto más central excede la centralidad de los demás. Se expresa como el ratio de ese exceso sobre su valor máximo posible para un grafo que contenga un determinado número de puntos. Las medidas de centralización referidas al grafo entero están todas basadas en las distancias entre puntos y todas ellas definen los grafos como centralizados en la medida en que sus puntos están todos cerca (Scott 1991; Freeman 1978/1979). La medida de centralización de la red tiene valores que oscilan entre 0 y 1. Las medidas alcanzan el valor 1 en redes tipo estrella, donde un solo actor domina las conexiones con todos los otros actores. En cambio, alcanzan el valor 0 cuando la red es totalmente completa, y todos los puntos están unidos entre sí por líneas, por lo que ningún actor es más central que otro, y por tanto, la red no está centralizada en ningún actor.

ALCANZABILIDAD DEL ACTOR MÁs CENTRAL: es el porcentaje de actores que el actor más central de la red puede alcanzar a un paso. Se calcula mediante el grado máximo en matriz dicotomizada dividido por el tamaño de la red menos uno. Por ejemplo, si la empresa que tiene más enlaces está conectada con 10 empresas, la alcanzabilidad del actor más central según grado es [10/(50-1)] 0,306. Al comparar esta alcanzabilidad máxima observamos qué red tiene un centro más aglutinador y cohesionador. Mediante este indicador observamos hasta que punto el centro de la red es un centro neurálgico y tiene la posibilidad de poder influenciar al resto de miembros de la red. Cuanto más alcanzabilidad tenga el actor más central, más centralizada es la red.

Proporción de Relaciones múltiples: se calcula dividiendo el total de los enlaces directos (grado) con la matriz dicotomizada, entre el total de los enlaces directos (grado) con la matriz no-dicotomizada. El resultado es la proporción de relaciones simples. Para obtener la proporción de enlaces múltiples se resta 1. Por ejemplo si la red corporativa de Italia esta formada por 534 enlaces (sumatorio total del grado con la matriz no-dicotomizada), y 336 son simples (sumatorio total del grado con la matriz dicotomizada), dividiendo 336 sobre 534, obtenemos la proporción de enlaces simples, en este caso $(0,629)$. Y conseguimos la proporción de enlaces múltiples restando uno $(1-0,629=0,371)$. 